\title{
Teacher in Reggio Emilia Approach: Educational Needs and Views
}

\author{
Cansu Meryem Birinci ${ }^{1^{*}}$ \\ ${ }^{1}$ Department of Educational Programs and Instruction, Near East University, Nicosia, N. CYPRUS
}

Received 12 September 2017 - Revised 12 October 2017 - Accepted 15 October 2017

\begin{abstract}
This study situates the educational needs of pre-school educators based on the essential aspects of the Reggio Emilia approach. A total of 156 pre-school educators agreed to participate in the study. The investigation combines both qualitative and quantitative research methods. The Reggio Emilia themed survey was conducted with the aim of gathering data on the educational needs related to the particular subject group. The survey consisted of two sections. The first part of the survey involved examining nine demographic factors, while the second part consisted of 49 Reggio Emilia based educational need items in total. All surveys were applied to the pre-school teachers' face-to-face in order to increase the reliability level of the research. In the survey, the opinions of the teachers were consulted in order to evaluate their needs in terms of the Reggio Emilia approach. Statistical analysis of the gathered data demonstrated that all teachers' have educational needs according to all of the determined dimensions of the approach. The dimensions included techniques, assessment and evaluation, tools and techniques and parental involvement in the survey. It was found that vocational seniority, vocational placement and family involvement matters affected the educational needs of the teachers' in various ways based on the approach.
\end{abstract}

Keywords: in-service training needs, pre-school education, Reggio Emilia approach, teacher, views

\section{INTRODUCTION}

It is undeniable that modern pre-school education has become a greater priority than in previous eras. Although the development of preschool education is different in every country, it can be easily observed that the level of awareness and sensitivity to the subject has considerably increased globally (Barnett, 2008). Studies conducted recently have demonstrated that cognitive development is more effective when it occurs during the early stages of childhood Therefore, there is a significant drive towards approaches that are applied in early childhood education with the aim of increasing efficiency. Consequently, the changing skills needs of today's world are motivating countries to modify their educational programmes (Rao et al., 2014). In this context, governments are now key actors in educational issues. In order to implement change, countries must firstly focus their efforts on education (Vargas-Baron \& Schipper, 2012) and, if the change is going to occur in the field of education, then sustainable teacher education should be provided (Kay, 2009). Cultural, political, and communal reflections are the main ingredients that formulate an educational programme, based on communal needs (Vargas-Baron \& Schipper, 2012). Many studies have proven that early childhood education has an influence over the development of a child's personality, habits, beliefs and attitudes, and this has led countries to increase their focus on pre-school teaching (Kaga \& Samuelsson, 2008).

As Pam (1996) highlighted, student centred approaches have increased in popularity in recent years. In this context, teachers' knowledge based on the field has been transformed. Today, student-centred mechanisms are preferred instead of traditional teacher-centred approaches. Rousseau, Dewey, Montessori, Piaget, Vygotsky and Gardner were pioneering theorists that conducted remarkable studies related to this particular subject. Several approaches that were developed many years ago still exist and maintain their level of influence. The Montessori, High Scope, Waldorf and Reggio Emilia approaches are particular examples (Edwards, 2002). All of the approaches 


\section{Contribution of this paper to the literature}

- This paper illustrates a strategic review on teaching according to Reggio Emilia approach.

- It highlights the needs of teachers related to the techniques, assessment and parental involvement in Reggio Emilia approach.

- The paper generates remarkable contribution to the literature especially based on early childhood and teacher education.

mentioned have common aspects, such as: student-centred, motivating, and aware of students' skills, attention and needs (Benson, Guess \& Siegel-Causey, 2005).

The Reggio Emilia Approach is a common approach that constructs all the aspects of the program on the basis of the children's needs, interests and differences (Helm \& Katz, 2001). Analysis conducted on the Reggio Emilia approach has revealed that numerous researchers are visiting Reggio Emilia in order to examine the approach in greater detail. Specialists and literature reviews claim that the Reggio Emilia approach provides strategic impacts on culture. Moreover, the success of the Reggio Emilia approach is encouraging schools in other countries to pay more attention to this educational method.

The Reggio Emilia approach was developed following reflections by Dewey, Gardner, Piaget and Vygotsky and is based on constructivism (İnan, Kantor \& Trundle, 2010). Although it has similarities with other approaches, there are also many differences, making it unique. Providing an environment for children in which they can build relationships, particularly with adults, is a significant aspect of their education. Thus, due to the fact that involving the parents in the educational process will consequently influence the children, this will have positive effects (Wexler, 2014).

Cadwell (2008) highlighted the fundamental principles of the Reggio Emilia approach, which include children being leaders and co-operators, the environment as the third teacher, the teacher as a guide, documentation as a communication tool, and the significance of family involvement.

With the Reggio Emilia approach, the walls around the child are removed. Strict rules, rigid attitudes and other traditional methods are the main features that constitute these barriers around children.

The Reggio Emilia approach helps children to develop problem-solving skills, and the hands-on approach provides children with the opportunity to explore and cooperate. Children benefit from the approach and experience the process of exploration, production, and hypothesis testing. Moreover, art, sculpture, drama, dance and music are particular means of expression for children. The "Hundred Languages of Children" poem represents one hundred symbolic methods of expression (Edwards, Forman \& Gandini 1998).

Learning is a process through which individuals develop skills by asking themselves questions. In this way, the creativity ability they develop assists them to adapt to changing cultures. The teacher is responsible for creating the most appropriate atmosphere for the students. Moreover, it is important that teachers increase their awareness of new technological developments (Gülbahar, 2016)

The popularity of the Reggio Emilia approach has increased dramatically in the past two decades and has become the most popular approach around the world. Nutbrown and Abbot (2001) also declared that children educated with the Reggio Emilia approach have increased tendencies for critical thinking and creativity, problemsolving abilities, cooperation and self-confidence. The authors acknowledge that the popularity of the approach has predominantly been motivated by these features. These features are essential, not only for personal development, but also for the strategic development of governments.

Moreover, according to LTS, (2006) demand and familiarisation visits to gather information about the Reggio Emilia approach have increased because almost every country in the world is increasing its demands for citizens that are able to cooperate, produce and think critically. Therefore, teachers should be comprehensively aware of the characteristics of the Reggio Emilia approach.

In this context, by considering the persuasive and constructive consequences of the Reggio Emilia approach, this research aims to investigate the educational needs of pre-school teachers' in terms of this approach. A literature review indicated that there have been no previous studies based on the educational needs of teachers using the Reggio Emilia approach. As the applicators of the approach, it is undeniable that the educational needs of preschool educators should be identified and satisfied. In this manner, the originality of this particular study derives from the in-service programme generated and presented for pre-school educators in the TRNC with the aim of meeting the requirements of the approach. In order to accomplish this goal, the following questions were addressed: 
1. What are the educational needs of pre-school teachers based on the Reggio Emilia approach?

2. Is the vocational seniority of teachers significant for their educational needs based on the Reggio Emilia approach?

3. Is the vocational placement of teachers significant for their educational needs based on the Reggio Emilia approach?

4. What are the opinions of pre-school educators' regarding the Reggio Emilia approach?

\section{METHOD}

\section{Research Model}

The research combined both qualitative and quantitative research methods.

\section{Participants}

The research participants were pre-school educators affiliated to the TRNC Ministry of Education in the 20142015 academic year. After a detailed exploration, 210 pre-school teachers were chosen. A total of 156 (74\%) teachers volunteered to participate in the study, illustrating that the study was robust. Considering that all the pre-school teachers volunteered to participate in the study, this increased the reliability of the data gathered through the analysis. The study included $16(10.3 \%)$ male and $140(89.7 \%)$ females. Their ages ranged from 23 to 55 years and they were from five cities in the TRNC (Kyrenia, Nicosia, Famagusta, İskele and Güzelyurt).

\section{Data Instruments}

In order to achieve the aims of the research, a questionnaire entitled "Educational Needs of Pre-School Educators based on the Reggio Emilia Approach" was generated (Birinci 2015). While quantitative data was collected using the questionnaire, qualitative data was gathered from the interviews.

\section{Educational Needs Analysis Questionnaire Based on the Reggio Emilia Approach (ENAQBREA)}

The study aimed to determine the educational needs of pre-school educators related to the Reggio Emilia approach. With this aim in mind, an in-depth review was conducted on national and international literature, and the subject was analysed comprehensively.

On the other hand, interviews were conducted with pre-school educators $(n=20)$. Interviewees were asked to write compositions detailing their needs related to the Reggio Emilia approach. Data gathered by the compositions was analysed through content analysis.

Subsequently, the professional advice was considered and comments based on the prepared questionnaire were used to correct or eliminate some of the items. Professionals in several fields were consulted $(n=6$, curriculum development specialists; $n=5$, assessment and evaluation specialists; and $n=4$, subject specialists).

The Delphi technique was preferred for the questionnaire in order to gather the most effective information about the views of the individuals participating in the research (Redman \& Thangaratinam, 2005). The advice of experts was sought continuously about other key features, in a similar manner to the technique determination during the generation of the questionnaire. Based on the recommendations provided by the experts, 76 items were excluded from the 125-item questionnaire.

The questionnaire was presented in two parts. The first part asked for demographic information including, gender, age, vocational experience, vocational placement, exhibition attendance, in-service training course participation and in-service training course effectiveness.

On the other hand, the second part of the questionnaire was divided into four main sections, which probed the educational needs of the pre-school teachers under the following headings: 'Technical factors based on the Reggio Emilia approach' (8 items), 'Assessment and evaluation in the Reggio Emilia approach' (5 items), 'Preparing activities, tools and techniques related to the Reggio Emilia approach' (29 items) and 'Parental cooperation and communication' (4 items).

For the second part of the study, the Likert-type scale was preferred, giving participants the opportunity to specify their agreement level for the items with five ordered answer levels. The levels were categorised as; 'I need quite a lot' (5), 'I need a lot' (4), 'I need at a moderate level' (3), 'I need a little' (2), and 'I do not need' (1). According to the calculations, the questionnaire's general Cronbach Alpha value was determined to be 0.95 . According to 
Cortina (1993), this determined value is regarded as highly reliable. The Cronbach Alpha calculation was developed by Cronbach (1951), in order to provide internal consistency for the statements.

\section{Interview Questionnaire Form Based on the Reggio Emilia Approach (IQFBREA)}

The interview form generated was semi-structured. Besides the level of participant needs related to the Reggio Emilia approach, the five pre-school teachers were asked to write a composition to provide their opinions. Before finalising the form, suggestions from experts $(n=13)$ (subject specialists $(n=4)$, curriculum development specialists $(n=6)$, assessment and evaluation specialists $(n=5)$ were requested regarding the prepared questions. The advice and recommendations of the specialists were adopted in order to establish the most appropriate questions. Furthermore, two Turkish language specialists reviewed the questions. The interview consisted of two questions. The first question was based on the application of the Reggio Emilia approach and the second was related to the potential side effects of its implementation. The interviews with participants were recorded and each interview lasted approximately 10-20 minutes.

\section{Data Collection}

After obtaining the necessary permission from the Ministry of National Education in the TRNC, interviews were made with the administrators of the schools related to the application. Within this process, data collection tools and application procedures were introduced carefully. Besides that, participants were informed that it was important to respond to the questions correctly in order to ensure that the results of the research are reliable. In this manner, questionnaires were distributed and collected after the period assigned for completion.

On the other hand, the Interview Questionnaire Form Based on the Reggio Emilia Approach was applied face-to-face. Before starting the interviews, participants were informed about the voice recorder and their permission was obtained for its use. Furthermore, the aim was to provide a comfortable environment in order to make the participants feel more relaxed.

\section{Data Analysis}

The gathered data was analysed using the Statistical Package for the Social Sciences (SPSS) 20.0 program. For quantitative data analysis, percentage, frequency, mean, standard deviation, one-way ANOVA and LSD techniques were adopted. On the other hand, for the qualitative data, content analysis was employed.

\section{RESULTS}

\section{The Educational Needs of Pre-school Educators Based on the Reggio Emilia Approach}

Opinions were sought from the participants in order to determine the general educational needs of pre-school educators regarding the Reggio Emilia approach under the four main dimensions. The data gathered from the questionnaire is demonstrated in Table 1.

As Table 1 illustrates, all pre-school teachers who participated in the research had a moderate to high level of need in all dimensions. When the items were examined in sequence, the mean and standard deviation values of the educators were $(M=3.73, s d=1.26)$, respectively regarding 'Preparing mini ateliers in the class'. This indicates that educators had a high level of educational need for this particular aspect. Similarly, the mean and standard deviation values for 'Arranging the piazza according to teaching' were $(\mathrm{M}=3.60, \mathrm{sd}=1.24)$, respectively, which proves that the level of educational need is high.

On the other hand, educators had a moderate level of educational need for 'Generating concept map' (M=2.92, $\mathrm{sd}=1.42$ ). Moreover, for the 'Making students write stories about the poem provided in the beginning of literacy education' statement, the mean and standard deviation were $(M=2.99$, and $\mathrm{sd}=1.39)$.

These results indicate that the educators participating in the research have higher levels of need for the situations that they do not practice frequently. In parallel to this, their level of educational need for the aspects they practice more frequently is at a low level. 
EURASIA J Math Sci and Tech Ed

Table 1. Descriptive Results of the Educational Needs of Pre-school Educators Based on the Reggio Emilia Approach

\begin{tabular}{|c|c|c|c|}
\hline Items Related to Educational Needs & $\mathbf{N}$ & Mean & SD \\
\hline Applying drama techniques & 156 & 3.46 & 1.40 \\
\hline Applying simulation techniques & 156 & 3.58 & 1.15 \\
\hline Use of vignettes & 156 & 3.41 & 1.21 \\
\hline Using dramatized analogies & 156 & 3.41 & 1.32 \\
\hline Generating concept map & 156 & 2.92 & 1.42 \\
\hline Applying pantomime techniques & 156 & 3.32 & 1.12 \\
\hline Applying peer-mediated instruction & 156 & 3.39 & 1.17 \\
\hline Applying compass role technique & 156 & 3.37 & 1.07 \\
\hline Evaluation with portfolio & 156 & 3.01 & 1.18 \\
\hline Benefitting from developmental assessment scale & 156 & 3.20 & 1.21 \\
\hline Generating observation form & 156 & 3.17 & 1.32 \\
\hline Using anecdotal record form & 156 & 3.06 & 1.15 \\
\hline Assessment with control list & 156 & 3.15 & 1.13 \\
\hline Assessment with rubrics & 156 & 3.32 & 1.22 \\
\hline Organizing of piazza according to teaching & 156 & 3.60 & 1.24 \\
\hline Evaluating hundred languages of children & 156 & 3.58 & 1.30 \\
\hline Making students paint backgrounds used in drama activities & 156 & 3.16 & 1.36 \\
\hline Determination of children's attention and orientation & 156 & 3.31 & 1.51 \\
\hline $\begin{array}{l}\text { Planning activities based on development of children's' interest and } \\
\text { orientation }\end{array}$ & 156 & 3.43 & 1.51 \\
\hline $\begin{array}{l}\text { Making students write stories for poems for the entrance to literacy } \\
\text { education }\end{array}$ & 156 & 2.99 & 1.39 \\
\hline Creating the safest environment for instructional activities & 156 & 3.19 & 1.62 \\
\hline Designing visual materials related to the topic to be instructed & 156 & 3.21 & 1.59 \\
\hline Applying problem-solving activities & 156 & 3.17 & 1.46 \\
\hline Applying creative thinking activities & 156 & 3.33 & 1.49 \\
\hline Organizing cooperative learning activities & 156 & 3.33 & 1.47 \\
\hline Preparing climbing hills & 156 & 3.14 & 1.28 \\
\hline Making students play finger games & 156 & 3.10 & 1.52 \\
\hline $\begin{array}{l}\text { Preparing rhythm instruments cooperatively with students for music } \\
\text { corners }\end{array}$ & 156 & 3.16 & 1.37 \\
\hline Benefitting from the conversation circle technique & 156 & 3.29 & 1.40 \\
\hline Mosaic nail play & 156 & 3.01 & 1.29 \\
\hline Organizing theatre activities around the topic to be studied & 156 & 3.22 & 1.22 \\
\hline Making students form filled toys & 156 & 3.11 & 1.25 \\
\hline Making origami & 156 & 3.07 & 1.34 \\
\hline Using circle time in activities & 156 & 3.16 & 1.36 \\
\hline Benefitting from recyclable wood for activities & 156 & 3.21 & 1.36 \\
\hline Knowing the rules of making Calder Mobile & 156 & 3.30 & 1.26 \\
\hline Using Calder Mobile & 156 & 3.20 & 1.26 \\
\hline Using Atelier with Atelierista & 156 & 3.48 & 1.28 \\
\hline Arranging from convex and concave mirrors & 156 & 3.42 & 1.40 \\
\hline Organizing mini ateliers for class & 156 & 3.73 & 1.26 \\
\hline Organizing rondines according to the level of students & 156 & 3.47 & 1.50 \\
\hline Organizing environment as third teacher & 156 & 3.42 & 1.32 \\
\hline Using wall paper for reflection games & 156 & 3.32 & 1.21 \\
\hline Using ropes in order to divide the class instead of screens & 156 & 3.10 & 1.30 \\
\hline Involving parents in poem reading activities & 156 & 3.12 & 1.37 \\
\hline Involving parents playing musical instruments for musical activities & 156 & 3.14 & 1.35 \\
\hline Demonstrating the timing diagram to families & 156 & 3.42 & 1.10 \\
\hline Cooperating with parents by communicating often & 156 & 3.16 & 1.48 \\
\hline Making puppets with parents & 156 & 3.06 & 1.35 \\
\hline Total & 156 & 3.26 & .77 \\
\hline
\end{tabular}


Table 2. Descriptive Statistical Results Based on Educational Needs Related to Reggio Emilia Approach According to the Vocational Experience of Pre-school Educators

\begin{tabular}{|c|c|c|c|c|}
\hline Dimension & Vocational Experience & $\mathbf{N}$ & Mean & SD \\
\hline \multirow{6}{*}{$\begin{array}{l}\text { Technical Factors Related to } \\
\text { Reggio Emilia Approach }\end{array}$} & $1-5$ & 38 & 3.36 & 0.76 \\
\hline & $6-10$ & 43 & 3.02 & 0.89 \\
\hline & $11-15$ & 20 & 3.55 & 1.03 \\
\hline & $16-20$ & 23 & 3.73 & 0.56 \\
\hline & $21+$ & 32 & 3.44 & 0.76 \\
\hline & Total & 156 & 3.36 & 0.83 \\
\hline \multirow{6}{*}{$\begin{array}{l}\text { Assessment and Evaluation } \\
\text { Factors in Reggio Emilia } \\
\text { Approach }\end{array}$} & $1-5$ & 38 & 3.30 & 0.81 \\
\hline & $6-10$ & 43 & 2.92 & 0.87 \\
\hline & $11-15$ & 20 & 3.25 & 0.90 \\
\hline & $16-20$ & 23 & 3.46 & 0.65 \\
\hline & $21+$ & 32 & 3.00 & 0.82 \\
\hline & Total & 156 & 3.15 & 0.83 \\
\hline \multirow{6}{*}{$\begin{array}{l}\text { Use of Tools and Activity } \\
\text { Organization Factors in } \\
\text { Reggio Emilia Approach }\end{array}$} & $1-5$ & 38 & 3.44 & 0.73 \\
\hline & $6-10$ & 43 & 2.96 & 1.02 \\
\hline & $11-15$ & 20 & 3.34 & 0.94 \\
\hline & $16-20$ & 23 & 3.58 & 0.57 \\
\hline & $21+$ & 32 & 3.24 & 0.79 \\
\hline & Total & 156 & 3.27 & 0.86 \\
\hline \multirow{6}{*}{$\begin{array}{l}\text { Parental Communication } \\
\text { and Cooperation Factors in } \\
\text { Reggio Emilia Approach }\end{array}$} & $1-5$ & 38 & 3.20 & 0.93 \\
\hline & $6-10$ & 43 & 3.13 & 1.06 \\
\hline & $11-15$ & 20 & 3.24 & 1.32 \\
\hline & $16-20$ & 23 & 3.40 & 0.66 \\
\hline & $21+$ & 32 & 3.05 & 0.95 \\
\hline & Total & 156 & 3.18 & 0.99 \\
\hline
\end{tabular}

\section{Descriptive Results of the Educational Needs of Pre-school Educator' Based on the Reggio Emilia Approach Regarding Vocational Experience Level}

In Table 2 descriptive results of the educational needs of pre-school educator' based on the Reggio Emilia approach regarding vocational experience level has been presented.

Table 2 illustrates the descriptive results of the vocational experience and educational needs of pre-school educators based on the Reggio Emilia approach.

The mean and standard deviation values towards the Reggio Emilia based technical factors were $(M=3.36$, $\mathrm{sd}=0.76)$ for $1-5$ years, $(\mathrm{M}=3.02$, $\mathrm{sd}=0.89)$ for 6-10 years, $(\mathrm{M}=3.55$, $\mathrm{sd}=1.03)$ for $11-20$ years and $(\mathrm{M}=3.44$ and $\mathrm{sd}==0.76)$ for 21 and more years of vocational experience level. Based on the outcomes, it could be stated that the educational needs of educators with 1-5 and 6-10 years of vocational experience in terms of the technical factors based on the approach is at a moderate level. On the other hand, the educational needs of educators' who have 11-15, 16-20 and 21 and more years of vocational experience is at a higher level compared to educators with 1-5 and 6-10 years of vocational experience. This could be because the information they acquired in their training is still fresh in their minds.

Concerning the second dimension, which was based on an assessment and evaluation of the Reggio Emilia approach, the mean and standard deviation values were $(M=3.30 \mathrm{sd}=0.81)$ for $1-5$ years, $(M=2.92$, sd=0.87) for 6-10 years, $(M=3.32, s d=0.90)$ for $11-15$ years, $(M=3.46, s d=0.65)$ for $16-20$ years and $(M=3.00, s d=0.82)$ for 21 and more years of vocational experience. The results illustrate that educators who have 1-5, 6-10, 11-15 and 21 and more years of vocational experience need a lower level of education based on the assessment and evaluation related to the Reggio Emilia approach compared to those who have 15-20 years of vocational experience.

The mean and standard deviation for dimension three, which relates to activity planning and tool usage in terms of the Reggio Emilia approach were $(M=3.44, \mathrm{sd}=0.73)$ for 1-5 years, $(\mathrm{M}=2.96, \mathrm{sd}=1.02)$ for $6-10$ years, $(\mathrm{M}=3.34$, $\mathrm{sd}=0.94)$ for $11-15$ years, $(\mathrm{M}=3.58, \mathrm{sd}=0.57)$ for $16-20$ years and $(\mathrm{M}=3.24, \mathrm{sd}=0.79)$ for 21 and more years of vocational experience. In this context, it could be claimed that educators who have 1-5 years of vocational experience need a higher level of education towards activity planning and tool usage related to the Reggio Emilia approach compared to those who have 6-10 and 11-15 years of vocational experience.

The mean and standard deviation values for the last dimension, which relates to communication and cooperation with parents in the Reggio Emilia approach were 
EURASIA J Math Sci and Tech Ed

Table 3. ANOVA Results of Educational Needs of Pre-School Educators Regarding the Reggio Emilia Approach According to Their Vocational Experience

\begin{tabular}{|c|c|c|c|c|c|c|c|}
\hline Dimension & $\begin{array}{l}\text { Source of } \\
\text { Variance }\end{array}$ & $\begin{array}{l}\text { Sum of } \\
\text { Squares }\end{array}$ & Sd & $\begin{array}{l}\text { Mean } \\
\text { Square } \\
\end{array}$ & $\mathbf{F}$ & $\mathbf{P}$ & Explanation \\
\hline \multirow{3}{*}{$\begin{array}{l}\text { Technical Factors Related } \\
\text { to RE Approach }\end{array}$} & Between Groups & 9.10 & 4 & 2.27 & 3.42 & 0.01 & $\begin{array}{l}P<0.05 \\
\text { Significant }\end{array}$ \\
\hline & Within Groups & 100.23 & 151 & 0.664 & & & \\
\hline & Total & 109.33 & 155 & & & & \\
\hline \multirow{3}{*}{$\begin{array}{l}\text { Assessment and Evaluation } \\
\text { in RE Approach }\end{array}$} & Between Groups & 6.29 & 4 & 1.57 & 2.32 & 0.06 & $\begin{array}{c}\mathrm{P}>0.05 \\
\text { Insignificant }\end{array}$ \\
\hline & Within Groups & 102.43 & 151 & 0.664 & & & \\
\hline & Total & 108.72 & 155 & & & & \\
\hline \multirow{3}{*}{$\begin{array}{l}\text { Use of Tools and Activity } \\
\text { Organization in RE } \\
\text { approach }\end{array}$} & Between Groups & 7.70 & 4 & 1.92 & 2.693 & 0.03 & $\begin{array}{c}\mathrm{P}<0.05 \\
\text { Significant }\end{array}$ \\
\hline & Within Groups & 107.93 & 151 & 0.715 & & & \\
\hline & Total & 115.63 & 155 & & & & \\
\hline \multirow{3}{*}{$\begin{array}{l}\text { Parental Cooperation and } \\
\text { Communication in RE } \\
\text { approach }\end{array}$} & Between Groups & 1.79 & 4 & 0.448 & 0.446 & 0.77 & $\begin{array}{c}\mathrm{P}>0.05 \\
\text { Insignificant }\end{array}$ \\
\hline & Within Groups & 151.65 & 151 & 1.00 & & & \\
\hline & Total & 153.44 & 155 & & & & \\
\hline
\end{tabular}

$(M=3.20, \mathrm{sd}=0.93)$ for 1-5 years, $(M=3.13, \mathrm{sd}=1.06)$ for 6-10 years, $(M=3.24, \mathrm{sd}=1.32)$ for 11-15 years, $(M=3$.

$40, \mathrm{sd}=0.66)$ for $16-20$ years and $(\mathrm{M}=3.05, \mathrm{sd}=0.95)$ for 21 and more years of vocational experience. According to these results, educators who have 1-5, 6-10, 11-15, and 21 and more years of vocational experience have moderate educational needs. On the other hand, educators who have 16-20 years of vocational experience have higher levels of educational needs towards communication and cooperation with parents in the Reggio Emilia approach.

In order to determine if the educational need types of pre-school educators based on 'Technical factors based on the Reggio Emilia approach', 'Assessment and evaluation in the Reggio Emilia approach', 'Preparing activities, tools and techniques related to the Reggio Emilia approach', and 'Parental cooperation and communication' differ significantly according to vocational experience, one-way variance analysis was applied. Subsequently, with the aim of determining the difference between the groups, least significant difference (LSD) tests were employed. The related data is provided in Table 3 .

Table 3 demonstrates that there is a meaningful difference in the value of $\left(\mathrm{F}_{(4-151)}=3.42, \mathrm{p}<0.05\right)$ between the vocational experience and the educational needs of the educators related to the technical factors of the Reggio Emilia approach. In order to observe the nature of the difference, LSD tests were conducted. Based on the results of these tests, it was observed that there is a significant difference between 6-10 and 11-15, 6-10 and 16-20 and 6-10 and 21 years. In all three cases, with mean values of 3.02, educators who have 6-10 years of experience have less educational needs related to technical factors based on the Reggio Emilia approach. This could be because educators in this age group have graduated more recently and therefore the information they have acquired is still fresh in their minds.

On the other hand, when the difference between the vocational experience and educational needs of educators related to assessment and evaluation based on the Reggio Emilia approach was examined, it was found that the value was $\left(\mathrm{F}_{(4-151)}=2.32, \mathrm{p}>0.05\right)$, which indicates that there is no significant difference between the two cases.

Concerning the value of $\left(\mathrm{F}_{(4-151)}=2.69, \mathrm{p}<0.05\right)$ regarding vocational experience and educational needs based on activity planning and tool usage, it was observed that there was a significant difference. After applying the LSD test in order to determine the type of the difference, it was found that there is a difference between 1-5, 6-10, 6-10 and 16-20 years of vocational experience and educational needs based on activity planning and tool usage. The analysis results illustrate that there is a difference in favour of the group with 6-10 years of vocational experience. In this context, it could be said that after 5 years of teaching, educators feel they have less educational needs in terms of activity planning and tool usage based on the Reggio Emilia approach.

The last dimension was based on communication and cooperation with parents using the Reggio Emilia approach. The difference between the vocational experience groups was found to be $\left(F_{(4-151)}=.446, p>0.05\right)$, which demonstrates that there is no meaningful significance. 
Table 4. Descriptive Statistical Results Based on Educational Needs Related to Reggio Emilia Approach According to Vocational Placement of Pre-school Educators

\begin{tabular}{|c|c|c|c|c|}
\hline Dimension & City & $\mathbf{N}$ & Mean & SD \\
\hline Technical & Nicosia & 41 & 3.15 & 0.84 \\
\hline Factors Related & Kyrenia & 34 & 3.62 & 0.77 \\
\hline to Reggio & Famagusta & 48 & 3.19 & 0.84 \\
\hline Emilia & Güzelyurt & 12 & 3.33 & 0.89 \\
\hline \multirow[t]{2}{*}{ Approach } & İskele & 21 & 3.76 & 0.71 \\
\hline & Total & 156 & 3.36 & 0.83 \\
\hline Assessment and & Nicosia & 41 & 3.08 & 0.97 \\
\hline Evaluation & Kyrenia & 34 & 3.26 & 0.94 \\
\hline Factors & Famagusta & 48 & 3.02 & 0.65 \\
\hline In Reggio & Güzelyurt & 12 & 3.20 & 0.83 \\
\hline Emilia & İskele & 21 & 3.37 & 0.72 \\
\hline Approach & Total & 156 & 3.15 & 0.83 \\
\hline Use of tools & Nicosia & 41 & 3.07 & 0.92 \\
\hline And Activity & Kyrenia & 34 & 3.52 & 0.89 \\
\hline Organization & Famagusta & 48 & 3.14 & 0.84 \\
\hline Factors In & Güzelyurt & 12 & 3.36 & 0.71 \\
\hline Reggio Emilia & İskele & 21 & 3.52 & 0.70 \\
\hline Approach & Total & 156 & 3.27 & 0.86 \\
\hline Parental & Nicosia & 41 & 2.88 & 0.93 \\
\hline Communication & Kyrenia & 34 & 3.33 & 1.04 \\
\hline And cooperation & Famagusta & 48 & 3.35 & 0.97 \\
\hline Factors in & Güzelyurt & 12 & 3.00 & 1.17 \\
\hline \multirow[t]{2}{*}{ Reggio Emilia } & İskele & 21 & 3.24 & 0.89 \\
\hline & Total & 156 & 3.18 & 0.99 \\
\hline
\end{tabular}

\section{Descriptive Results of the Educational Needs of Pre-school Educators Based on the Reggio Emilia Approach Regarding Their Vocational Placements}

Table 4 illustrates the descriptive statistical results in terms of the vocational placement and educational needs of pre-school educators based on the Reggio Emilia approach.

The mean and standard deviation values were $(M=3.15, \mathrm{sd}=0.84)$ for Nicosia, $(\mathrm{M}=3.62$, sd=077) for Kyrenia, $(\mathrm{M}=3.19, \mathrm{sd}=0.84)$ for Famagusta, $(\mathrm{M}=3.33, \mathrm{sd}=0.89)$ for Güzelyurt and $(\mathrm{M}=3.76, \mathrm{sd}=0.71)$ for İskele for the technical factors related to the Reggio Emilia approach. According to this table, the educational needs of educators working in Nicosia, Famagusta and Güzelyurt towards this particular dimension are at a moderate level. On the other hand, it was found that educators in Kyrenia and İskele have higher levels of educational needs compared to other groups.

The mean and standard deviation values for the second dimension, which is related to the assessment and evaluation in the Reggio Emilia approach were $(M=3.08$, sd=0.97) in Nicosia, $(M=3.26, s d=0.94)$ in Kyrenia, $(M=3.02$, $\mathrm{sd}=0.65)$ in Famagusta, $(\mathrm{M}=3.20 \mathrm{sd}=0.83)$ in Güzelyurt and $(\mathrm{M}=3.37, \mathrm{sd}=0.72)$ in İskele. In this context, it is evident that educators working in all the cities studied have a moderate level of educational needs towards evaluation and assessment in the Reggio Emilia dimension.

Concerning dimension three, activity planning and tool usage in the Reggio Emilia approach, the mean and standard deviation values were $(M=3.07$, sd=0.92) for Nicosia, $(M=3.52$, sd=0.89) for Kyrenia, $(M=3.52$, sd=0.89) for Famagusta, $(\mathrm{M}=3.36, \mathrm{sd}=0.71)$ for Güzelyurt and $(\mathrm{M}=3.52, \mathrm{sd}=0.70)$ for İskele. According to this table, the educational needs of pre-school educators towards activity planning and tool usage in the Reggio Emilia approach are at a moderate level for those working in Nicosia, Famagusta and Güzelyurt. On the other hand, the educational needs for educators in Kyrenia and İskele are at a high level.

Concerning the last dimension, communication and cooperation with parents in the Reggio Emilia approach, the mean and standard deviation values were found to be $(\mathrm{M}=2.88, \mathrm{sd}=0.93)$ in Nicosia, $(\mathrm{M}=3.33, \mathrm{sd}=1.04)$ in Kyrenia, $(M=3.35, s d=0.97)$ in Famagusta, $(M=3.00, s d=1.17)$ in Güzelyurt and $(M=3.24, s d=0.89)$ in İskele. According to this data, educators working in all the cities have a moderate level of educational needs towards the dimension based on communication and cooperation with parents in the Reggio Emilia approach.

In order to examine whether the educational need types of pre-school educators based on 'Technical factors based on the Reggio Emilia approach', 'Assessment and evaluation in the Reggio Emilia approach', 'Preparing 
Table 5. ANOVA Results of Educational Needs of Pre-school Educators Relating to the Reggio Emilia Approach According to Their Vocational Placements

\begin{tabular}{|c|c|c|c|c|c|c|c|}
\hline Dimension & Source of Variance & $\begin{array}{l}\text { Sum of } \\
\text { Squares }\end{array}$ & Sd & $\begin{array}{c}\text { Mean } \\
\text { Square }\end{array}$ & $\mathbf{F}$ & $\mathbf{P}$ & Explanation \\
\hline \multirow{3}{*}{$\begin{array}{l}\text { Technical Factors Related } \\
\text { to RE Approach }\end{array}$} & Between Groups & 8.82 & 4 & 2.20 & 3.31 & 0.01 & $\mathrm{P}<0.05$ Significant \\
\hline & Within Groups & 100.51 & 151 & 0.666 & & & \\
\hline & Total & 109.33 & 155 & & & & \\
\hline \multirow{3}{*}{$\begin{array}{l}\text { Assessment and } \\
\text { Evaluation in } \\
\text { RE Approach }\end{array}$} & Between Groups & 2.47 & 4 & 0.620 & 0.881 & 0.47 & $\mathrm{P}>0.05$ Insignificant \\
\hline & Within Groups & 106.25 & 151 & 0.704 & & & \\
\hline & Total & 108.72 & 155 & & & & \\
\hline \multirow{3}{*}{$\begin{array}{l}\text { Use of Tools and Activity } \\
\text { Organization in RE } \\
\text { approach }\end{array}$} & Between Groups & 5.97 & 4 & 1.492 & 2.05 & 0.90 & $\mathrm{P}>0.05$ Insignificant \\
\hline & Within Groups & 109.66 & 151 & 0.726 & & & \\
\hline & Total & 115.63 & 155 & & & & \\
\hline \multirow{3}{*}{$\begin{array}{l}\text { Parental Cooperation and } \\
\text { Communication in RE } \\
\text { approach }\end{array}$} & Between Groups & 6.44 & 4 & 1.611 & 1.65 & 0.16 & $P>0.05$ Insignificant \\
\hline & Within Groups & 147.00 & 151 & 0.974 & & & \\
\hline & Total & 153.44 & 155 & & & & \\
\hline
\end{tabular}

activities, tools and techniques related to the Reggio Emilia approach', and 'Parental cooperation and communication' differ significantly regarding the teachers' vocational placement, one-way variance analysis was conducted. Accordingly, with the aim of determining the type of the difference between the groups, LSD tests were applied. The data relating to this analysis is provided in Table 5.

As seen in Table 5, there is a meaningful difference in the value $\left(F_{(4-151)}=3.31, p<0.05\right)$ between the vocational placement and educational needs towards the technical factors related to the Reggio Emilia approach. The applied LSD tests demonstrate that there is a significant difference between the Nicosia- Kyrenia, Nicosia- İskele and Famagusta - İskele groups. Moreover, there is a significant difference in favour of the city of Nicosia in the first two cases. On the other hand, the difference in the third case is in favour of Famagusta. In this context, it could be said that educators working in Nicosia have a lower level of educational needs in terms of the technical dimension.

Concerning the second dimension related to assessment and evaluation in the Reggio Emilia approach, the value was calculated as $\left(\mathrm{F}_{(4-151)}=.881, \mathrm{p}>0.05\right)$. This analysis indicates that there is no significant difference between vocational placements and educational need levels towards assessment and evaluation in the Reggio Emilia approach.

Similarly, in the third dimension based on activity planning and tool use in the Reggio Emilia approach, the value was determined as $\left(\mathrm{F}_{(4-151)}=2.05, \mathrm{p}>0.05\right)$, illustrating that there is no significant difference between the educational need levels in terms of the dimension and vocational placement.

Concerning the last dimension based on communication and cooperation with parents in the Reggio Emilia approach, the value determined was $\left(\mathrm{F}_{(4-151)}=1.65, \mathrm{p}>0.05\right)$. This value indicates that there is no significant difference between vocational placement and educational need levels towards communication and cooperation in the Reggio Emilia approach.

\section{Opinions of Pre-school Educators towards the Reggio Emilia Approach}

In order to meet the goals of the qualitative research in the study, the opinions of the educators were sought. The participants were invited to answer two specific questions in the study. When asked 'What are your thoughts about the implementation of the Reggio Emilia approach?' a considerable number of educators claimed that students in their classes would be more active, creative, productive and respectful to each other. They also suggested that the education with this approach would have more permanence by saying 'Children are quite active in this approach', 'Teaching becomes clear and visible with the Reggio Emilia approach', and 'Children can be very productive with this approach'. It could be said that educators are positive about the application of the Reggio Emilia approach; hence, they are willing to implement it in their classes.

The second question asked educators about the potential side effects of implementing the Reggio Emilia approach in their classes. The answers provided illustrate that teachers have concerns about their level of proficiency in relation to the implementation of the approach. Furthermore, they stated that they also had doubts related to family persuasion, timing, activity planning and assessment and evaluation dimensions by saying 'The approach is quite useful for our country but I do not know much about it', 'Families will worry that their kids will become dirty' and 'I do not know if I can manage the lessons without an educational curriculum'. Considering the answers provided by the pre-school educators, although they are willing to implement this particular approach, they do not perceive themselves to be sufficiently professional for effective application. Hence, an in-service training 
programme related to the Reggio Emilia approach was generated in order to meet the needs of the educators and to determine solutions to the potential side effects of its implementation.

\section{DISCUSSION}

After the investigation for this particular research, it was found that all of the pre-school educators that participated in the study have low or moderate levels of educational needs towards all dimensions of the questionnaire applied. The results indicate that all educators need education for all aspects determined for the Reggio Emilia approach. Furthermore, according to the descriptive statistical results, vocational experience revealed significant differences in their educational need levels. The values for this particular aspect showed that, in general, the educators who are new to teaching have more information, and accordingly have a lower level of educational need regarding the Reggio Emilia approach compared to the educators who are more experienced in the field. Similarly, vocational placement groups differ significantly from dimension to dimension when compared to each other. These outcomes prove that educators have educational needs related to different dimensions of the Reggio Emilia approach. Moreover, the qualitative data gathered in the interviews also indicated that the majority of the educators are willing to apply the Reggio Emilia approach in their teaching and culture, although they believe that their knowledge is not sufficient to apply it and they have concerns about family persuasion, timing and activity planning. However, documentation is one of the most remarkable issues that that concerned the participants. The lack of time and information about this particular assessment type are also concerns for the participants. Nevertheless, according to the majority of the teachers, technology is a solution for this particular issue as it was believed that technology could be used as a documentation instrument. Research based on digital documentation conducted by Rinaldi (2001) suggested that devices such as iPods or iPads could be employed in order to achieve effective outcomes from documentation and could facilitate the process of recording, note taking and taking photographs. In this respect, an in-service programme should be generated according to the needs of the participants determined in the investigation, which could be applied to satisfy the needs and prevent the potential side effects of the implementation of the Reggio Emilia approach.

According to Kay (2009), teachers constantly aim to update the knowledge on the improvements in the field of education. Furthermore, in-service training is significant in improving the skills of workers in all aspects. Meeting the deficiencies of the workers and eliminating the negative side effects of new implementations could be achieved through in-service training (Nakpodia, 2008; Udofia \& Ikpe, 2012; Aitken, 2004). As observed from the outcomes of the research, the statements made by the authors coincide significantly. Canman (2000) suggested that not only does in-service training make employees more effective in specific areas, but also creates positive effects for the organization, such as teaching employees to collaborate in order to achieve specific goals.

Sak (2014) clarified that in order to achieve curriculum goals, educators should play a key role because the activities ultimately implemented by the teachers themselves. Thus, being informed about the developments in modern culture would lead them to perform more effectively.

Educating skills should be sufficiently flexible to adapt to technological improvements, the environment and expectations (Brand, 1987; Heyneman, Haynes; Kılınç, 2016).

Çelikten, Şanal and Yeni (2005) categorized teacher skills into two key dimensions. One dimension reflects personal characteristics and the other vocational characteristics. Moreover, the authors divided vocational characteristics into three sections that combine liberal education, subject area mastery and teaching vocational knowledge. Taking into account all the expressions made by the authors, this indicates that educators play a key role in education and are responsible for educating themselves according to developments in modern culture.

\section{CONCLUSION}

The main aim of the research was to analyse the fundamental needs of pre-school teachers working in nurseries affiliated to the TRNC Ministry of Education related to the determined dimensions of the Reggio Emilia approach. Data gathered through the quantitative research method demonstrated that, in general, all the pre-school teachers that participated in the research had educational needs related to the determined dimensions of the Reggio Emilia approach. Moreover, it was observed that the vocational experience and vocational placement of teachers create significant differences related to the educational needs of pre-school educators. Furthermore, according to the interview results, educators perceived that the Reggio Emilia approach could be effectively introduced in their culture, although they believe that they do not have sufficient skills and knowledge about the application of the approach. As a consequence, it was determined that pre-school educators should receive training regarding this particular approach. 


\section{RECOMMENDATIONS}

Using the data gathered using the quantitative and qualitative methods, an in-service programme based on the Reggio Emilia approach was developed in order to improve the skills of educators in terms of its dimensions. Hence, after the in-service programme, the approach could become applicable to the specific culture in the schools in the TRNC. A Reggio Emilia based curriculum is strongly recommended for development following the in-service programme to ensure the sustainability of the programme in the upcoming years.

\section{REFERENCES}

Abbott, L., \& Nutbrown, C. (2001). Experiencing Reggio Emilia: Implications for Preschool Provision. Buckingham. UK: Open University Press.

Akinbode, J. F. (1996). Staff development. Journal of the Institute of Personnel Management of Nigeria, 12(2), 52-57.

Barnett, W. S. (2008). Preschool education and its lasting effects: Research and policy implications. Boulder and Tempe: Education and the Public Interest Center \& Education Policy Research Unit. Retrieved on 20.04.16 from http://epicpolicy.org/publication/preschooleducation

Benson, H. A., Guess, D., \& Siegel-Causey, E. (1985). Concepts and Issues Related to Choice Making and Autonomy among Persons with Severe Disabilities. Journal of the Association for Persons with Severe Handicaps, 10, 79-86.

Brand, S. (1987). The Media Lab: inventing the future at MIT. New York: Viking.

Bray, M., Chen, E., Ip, P., Lee, D., Rao, N., Shaeffer, S., Sun, J., Wong, J. M. S., Weekes, B., \& Young, M. (2014). Early childhood development and cognitive development in developing countries: A rigorous literature review. Department for International Development. Faculty of Education.

Cadwell, L. B. (2008). The Reggio Approach to Early Childhood Education Bringing Learning to Life. New York. Teachers College Press.

Canman, D. (2000). Insan Kaynakları Yönetimi. Ankara. Yargı Yayını.

C,̣likten, M., Șanal, M. \& Yeni, Y. (2005). Ögretmenlik meslegi ve özellikleri. Dokuz Eylui Un̈iversitesi. Sosyal Bilimler EnstitüüDergisi, 19(2), 207-237.

Cortina, J. M. (1993). What Is Coefficient Alpha? An Examination of Theory and Applications. Journal of Applied Psychology, 78(1), 301-321.

Cronbach, L. J. (1954). Educational psychology. New York: Harcourt Brace.

Edwards, C. (2002). Three Approaches from Europe: Waldorf, Montessori, and Reggio Emilia. Early Childhood Research \& Practice, 4, no. 1. Retrieved from http://ecrp.uiuc.edu/v4nl/edwards.html

Edwards, C., Forman, G., \& Gandini, L. (1998). The Hundred Languages of Children. The Reggio Emilia ApproachAdvanced Reflections (2nd Ed.). London: Ablex Publishing.

Gülbahar, B. (2016). Views of the Teachers on the Behaviors and the Personal Characteristics of the School Principal Which are Effective in Formation of a Democratic School Environment. The Anthropologist. International Journal of Contemporary and Applied Studies of Man, 23(1).21-32.

Haynes, K. T., \& Heyneman, S. (2004). International uses of education technology: threats and opportunities. Paris: IEEP Publications.

Helm, H., \& Katz, L. (2001). Young Investigators: The Project Approach in the Early Years. New York: Teachers College Press.

İnan, H. Z., Kantor, R., \& Trundle, K. C. (2010). Understanding natural sciences education in a Reggio Emiliainspired preschool. Journal of Research in Science Teaching, 47(10), 1186-1208.

Kaga, Y., \& Samuelsson, I. P. (2008). UNESCO- The contribution of early childhood education to a sustainable society. France.

Kay, K. (2009). Preparing every child for the 21st century, partnership for 21st century skills. Retrieved on 23 March 2012 from http://www.cpb.org/stations/reports/PreparingChildren21stCentury.pdf

Kılınç, H. H. (2016). Teachers' Perception of 2nd Grade English Curriculum of Primary School in Turkey. The Anthropologist. International Journal of Contemporary and Applied Studies of Man, 251-266.

Krechevsky. M., \& Rinaldi, C. (2001). Making learning visible: Children as individual and group learners. Reggio Emilia, Italy: Reggio Children, 78-89.

LTS. (2006). The Reggio Emilia Approach to Early Years Education. LTS. Glasgow. Retrieved on 4 April 2016 from http://www.educationscotland.gov.uk/Images/ReggioAug06_tcm4-393250.pdf 
Nakpodia, E. D. (2008). The role of Educational administration in the promotion of in-service teacher education for primary school teachers in Nigeria. Current issues in educational management in Nigeria. Benin City: Ambik Press.

Pam, C. (1996). Child-Centered Early Childhood Education In Eastern Europe: The Step by Step Approach. Childhood Education, 72(6), p.337-341.

Redman, C. W., \& Thangaratinam, S. (2005). The Delphi Technique. The obstetrician \& Gynaecologist. (7), 120-125.

Rinaldi, C. (2001). Documentation and assessment: What is the relationship? In C. Giudici, Rinaldi, C. and Kreschevsky, M. (eds) Making Learning Visible: Children as Group and Individual Learners, Reggio Children, pp.78-89.

Robertson, E. (2008). Teacher education in a democratic society. Learning and Teaching the Practices of Democratic Participation, in Marilyn Cochran-Smith, Sharon Feiman-Nemser, and John McIntyre, Eds., The Handbook of Research on Teacher Education, 3rd edition (New York: Taylor \& Francis Group and The Association of Teacher Educators, 2008), pp. 27-44.

Udofia, U., İ., \& Ikpe, U. N. (2012). Administration of In-Service Training and Teachers Attitude to Work in Private Secondary Schools in Cross River State of Nigeria. International Journal of Academic Research in Business and Social Sciences, 2(10), 255-265.

Vargas-Baron, E., \& Schipper, J. (2012). Review of Policy and Planning Indicators in Early Childhood. RISE Institute (commissioned by UNESCO, Paris).

Wexler, A. (2004). A theory for living: Walking with Reggio Emilia. Art Education, 57(6), 13-19.

\section{http://www.ejmste.com}

